\title{
Concurrent neuromechanical and functional gains following upper-extremity power training post-stroke
}

\author{
Carolynn Patten ${ }^{1,2^{*}}$, Elizabeth G Condliffe ${ }^{3,4}$, Christine A Dairaghi ${ }^{5}$ and Peter S Lum ${ }^{6,7,8}$
}

\begin{abstract}
Background: Repetitive task practice is argued to drive neural plasticity following stroke. However, current evidence reveals that hemiparetic weakness impairs the capacity to perform, and practice, movements appropriately. Here we investigated how power training (i.e., high-intensity, dynamic resistance training) affects recovery of upper-extremity motor function post-stroke. We hypothesized that power training, as a component of upper-extremity rehabilitation, would promote greater functional gains than functional task practice without deleterious consequences.
\end{abstract}

Method: Nineteen chronic hemiparetic individuals were studied using a crossover design. All participants received both functional task practice (FTP) and HYBRID (combined FTP and power training) in random order. Blinded evaluations performed at baseline, following each intervention block and 6-months post-intervention included: Wolf Motor Function Test (WMFT-FAS, Primary Outcome), upper-extremity Fugl-Meyer Motor Assessment, Ashworth Scale, and Functional Independence Measure. Neuromechanical function was evaluated using isometric and dynamic joint torques and concurrent agonist EMG. Biceps stretch reflex responses were evaluated using passive elbow stretches ranging from 60 to 180\%/s and determining: EMG onset position threshold, burst duration, burst intensity and passive torque at each speed.

Results: Primary outcome: Improvements in WMFT-FAS were significantly greater following HYBRID vs. FTP $(p=.049)$, regardless of treatment order. These functional improvements were retained 6-months post-intervention $(p=.03)$.

Secondary outcomes: A greater proportion of participants achieved minimally important differences (MID) following HYBRID vs. FTP $(p=.03)$. MIDs were retained 6-months post-intervention. Ashworth scores were unchanged ( $p>$.05).

Increased maximal isometric joint torque, agonist EMG and peak power were significantly greater following HYBRID vs. FTP $(p<.05)$ and effects were retained 6 -months post-intervention $\left(p^{\prime} s<.05\right)$. EMG position threshold and burst duration were significantly reduced at fast speeds $(\geq 120 \% / s)\left(p^{\prime} s<0.05\right)$ and passive torque was reduced post-washout $(p<.05)$ following HYBRID.

(Continued on next page)

\footnotetext{
* Correspondence: patten@phhp.ufl.edu

'Brain Rehabilitation R\&D Center (151A), Malcolm Randall VA Medical Center, 1601 SW Archer Rd, Gainesville, FL 32608, USA

${ }^{2}$ Department of Physical Therapy, University of Florida, Gainesville, FL, USA

Full list of author information is available at the end of the article
} 
(Continued from previous page)

Conclusions: Functional and neuromechanical gains were greater following HYBRID vs. FPT. Improved stretch reflex modulation and increased neuromuscular activation indicate potent neural adaptations. Importantly, no deleterious consequences, including exacerbation of spasticity or musculoskeletal complaints, were associated with HYBRID. These results contribute to an evolving body of contemporary evidence regarding the efficacy of high-intensity training in neurorehabilitation and the physiological mechanisms that mediate neural recovery.

Keywords: Stroke, Recovery, Function, Upper-extremity, EMG, Strength(ening), Hemiparesis, Hypertonia, Muscle strength, Rehabilitation

\section{Background}

Upper-extremity hemiparesis is among the most significant and persistent physical disabilities following stroke and represents a critical barrier to independence [1]. While the problem is well recognized, there is little evidence demonstrating the most effective approach for promoting functional motor recovery of the hemiparetic upper-extremity [2].

Prominent manifestations of compromised motor control following stroke include: impaired inter-segmental coordination [3], hyperreflexia or spasticity [4], and weakness [5]. Rather than mechanical factors such as muscle fibre type or cross-sectional area, hemiparetic weakness results predominantly from disorganized neuromotor output, including impaired descending motor drive, and activation impairment [6,7]. Accumulating evidence suggests that weakness plays a more significant role than traditionally believed and contributes directly to compromised motor function post-stroke [8-10]. In contrast to fundamental traditional clinical tenets [11], contemporary research demonstrates that neither highexertion activities nor resistance training, per se, exacerbate spasticity [12-16]. Lower extremity resistance exercise has revealed improvements in functional task performance including: walking, rising from a chair, and stair climbing [10,17-19] and self-perceived disability [20] in persons post-stroke. However, the role of strength $[8,9]$ and the effects of strengthening have only recently been systematically investigated in the hemiparetic upper-extremity [21-23].

Here we investigated two forms of upper-extremity rehabilitation for persons post-stroke: 1) functional task practice (FTP) and 2) functional task practice combined with upper-extremity power training (i.e., dynamic highintensity resistance training) which we refer to as HYBRID. We hypothesized that inclusion of power training in upper-extremity rehabilitation would produce greater effects on clinical and neuromechanical indicators of functional motor recovery without producing detrimental effects including exacerbation of spasticity. Because there is little evidence to support inclusion of either high-intensity or resistance training, we conducted a clinical trial to investigate the feasibility, safety and efficacy of upper-extremity power training in persons post-stroke. Our observations confirm our hypothesis and demonstrate positive functional outcomes, increased strength and joint power, improved reflex modulation and retention of treatment effects in the absence of additional intervention. Importantly, our findings indicate no negative consequences (i.e., exacerbation of spasticity, joint pain or injury) resulting from inclusion of power training in upper-extremity rehabilitation.

\section{Methods \\ Participants}

We studied nineteen individuals in the chronic phase of recovery, operationally defined as 7-18 months poststroke. All participants had completed directly supervised medical rehabilitation programs and agreed to maintain participation in community-based physical activities (e.g., adaptive physical education, support groups, individual work with a personal trainer, etc.) constant through the full period of study including a 6-month retention interval. Compliance with this agreement was monitored through activity logs kept by participants (and their spouses/caregivers), which were returned at each evaluation session and reviewed by the Principal Investigator and study personnel.

Inclusion criteria for participation were: i) clinical presentation of a single, unilateral stroke; ii) ability to produce active, volitional movement out of the plane of gravity at the shoulder and elbow; iii) demonstration of at least $10^{\circ}$ of active wrist extension, $10^{\circ}$ active thumb abduction, and $10^{\circ}$ active extension of any two digits, three times within one minute; iv) freedom from significant upper extremity joint pain, range of motion limitations, and/or sensory deficits as revealed by clinical examination [24]. The Neurobehavioral Cognitive Status Exam ("Cognistat") [25] was administered to determine participants' abilities to comprehend, provide decisional consent, learn and follow three step commands. Diagnosis of stroke, including mechanism and location was confirmed by review of medical records, radiology reports and documentation by the participant's referring physician. Participants were recruited from the sponsoring institution and the greater community, which 


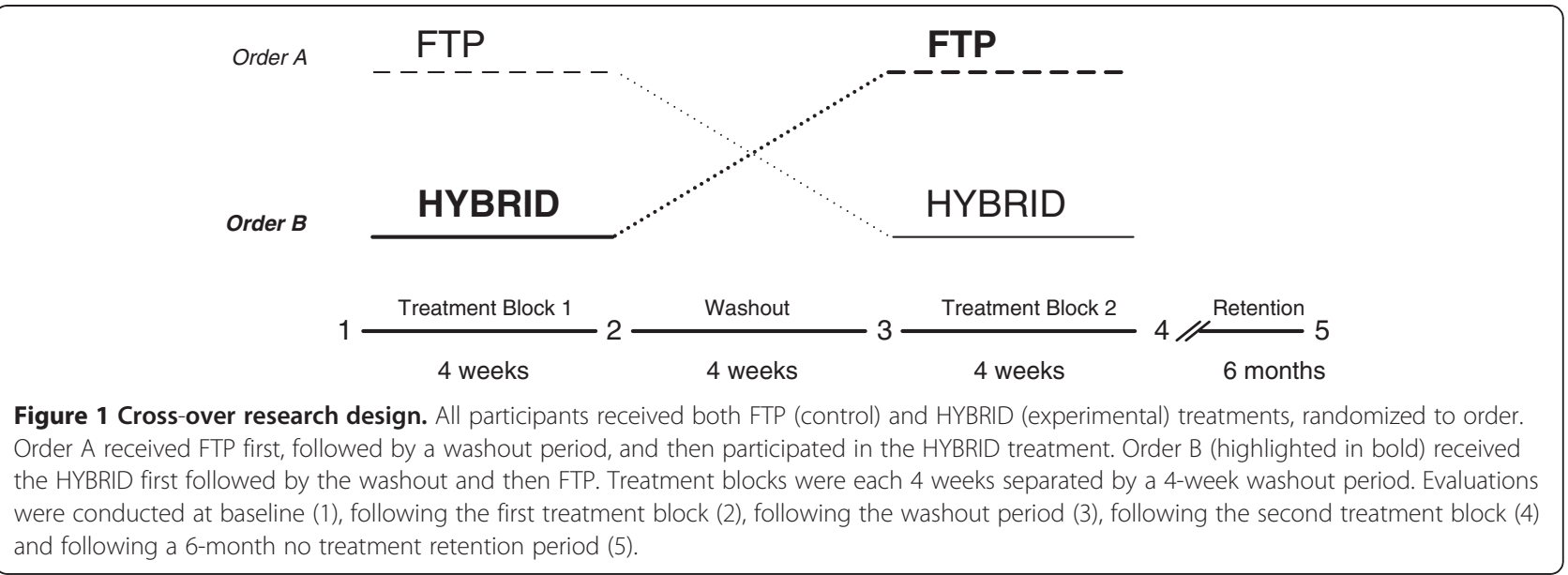

facilitated enrollment of a demographically representative participant sample. All procedures were approved by the Stanford University Panels on Human Subjects in Research. Written, informed consent was provided by all participants prior to enrollment, randomization and involvement in study activities.

\section{Study design}

The study involved a randomized, double-blind crossover design [26]. All participants received both the control (FTP) and experimental (HYBRID) interventions, randomized to treatment order (Figure 1). Treatment Order A was operationally defined as FTP followed by HYBRID and Treatment Order B as HYBRID followed by FTP. Treatment was delivered in two 4-week blocks of twelve sessions each, interspersed with a 4-week washout period. Thus, each participant received a total of 24 sessions of one-on-one treatment with a physical therapist over a 12week period. All participants were treated by the same physical therapist. Blinded evaluators conducted clinical and neuromechanical assessments at: baseline, following each block of therapy, following the washout period, and again at 6-months post-intervention.

\section{Study population}

Of the 48 persons who inquired regarding study participation, 23 met eligibility criteria. Nineteen persons agreed to enrollment and were randomized. The flow of study participants through all stages of the study is depicted in Figure 2. Participant characteristics, demographics and baseline clinical metrics are reported in Table 1.

\section{Randomization and blinding}

The shoulder-elbow portion (30 points) of upper-extremity Fugl-Meyer motor score [27] was used to classify participants as higher ( $\geq 20$ points) and lower ( $<20$ points) functioning. Separate random orders prepared at study initiation for higher and lower functioning participants

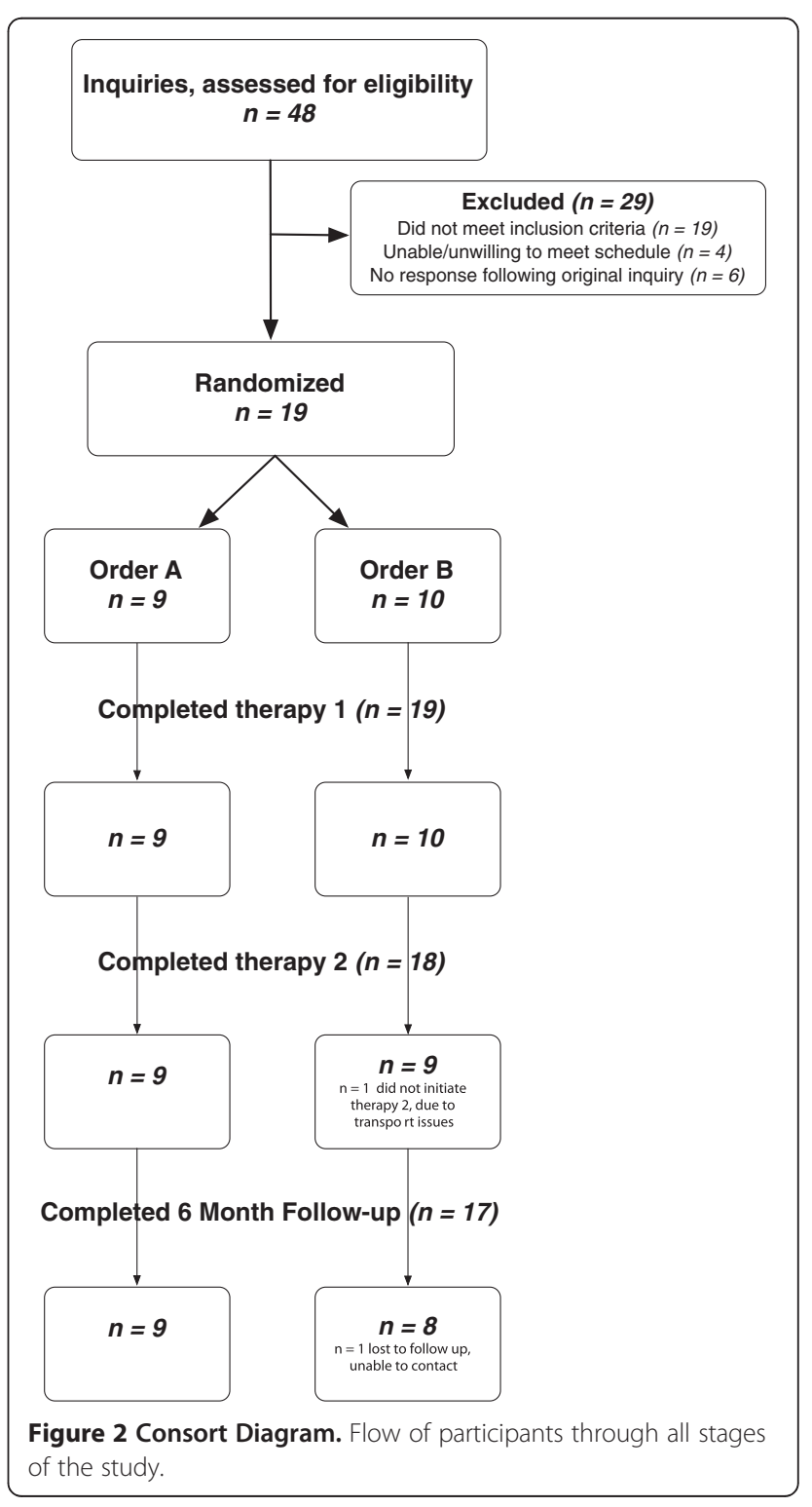


Table 1 Participant demographics

\begin{tabular}{|c|c|c|}
\hline \multirow[t]{2}{*}{ Characteristic } & \multirow{2}{*}{$\begin{array}{l}\text { Order } A \\
n=9\end{array}$} & \multirow{2}{*}{$\begin{array}{l}\text { Order B } \\
\mathrm{n}=10\end{array}$} \\
\hline & & \\
\hline Mean age, yr $( \pm S D)$ & $64.7(9.7)$ & $72.9(11.1)$ \\
\hline Gender & $6 \mathrm{M}, 3 \mathrm{~F}$ & $9 \mathrm{M}, 1 \mathrm{~F}$ \\
\hline Time since onset, mo & $14.7(2.7)$ & $11.4(4.3)$ \\
\hline Side affected & $5 \mathrm{~L}, 4 \mathrm{R}$ & $5 \mathrm{~L}, 5 \mathrm{R}$ \\
\hline \multicolumn{3}{|l|}{ Mechanism of Stroke } \\
\hline Ischemic & 7 & 7 \\
\hline Hemorrhagic & 2 & 2 \\
\hline Infarct w/hemorrhagic conversion & & 1 \\
\hline \multicolumn{3}{|l|}{ Lesion location } \\
\hline Cortical & 6 & 3 \\
\hline Subcortical & 3 & 2 \\
\hline Not specified & & 5 \\
\hline $\begin{array}{l}\text { Upper-extremity Fugl-Meyer Score } \\
\text { (total } 66 \text { points) }\end{array}$ & $37.3(13.1)$ & $43.2(10.6)$ \\
\hline $\begin{array}{l}\text { Fugl-Meyer Shoulder-Elbow Score } \\
\text { (total, } 30 \text { points) }\end{array}$ & $18.9(5.4)$ & $20.4(6.0)$ \\
\hline $\begin{array}{l}\text { Ashworth Score (shoulder + elbow) } \\
\quad \text { (total } 8 \text { points) }\end{array}$ & $3.9(1.5)$ & $3.4(2.0)$ \\
\hline $\begin{array}{l}\text { Wolf Motor Function Test } \\
\text { FAS (range 0-5) }\end{array}$ & $2.9(1.1)$ & $3.1(0.8)$ \\
\hline $\begin{array}{l}\text { Functional Independence Measure } \\
\text { (Total } 91 \text { points) }\end{array}$ & $84.3(5.0)$ & $76.4(14.1)$ \\
\hline
\end{tabular}

Diagnosis of stroke and lesion location were confirmed via review of the participant's medical records. Data presented are mean $( \pm S D)$.

were allocated to sealed envelopes and kept by the study coordinator in a locked drawer. Following baseline clinical assessment, the blinded evaluator informed the study coordinator of the participant's hemiparetic severity (i.e., higher $\mathrm{v}$. lower). The coordinator selected a sequentially numbered sealed envelope from the appropriate group (i.e., higher vs. lower). This envelope was given to the treating physical therapist who broke the seal to reveal the assignment to treatment order. Stratification on the basis of hemiparetic severity was done to assure baseline equivalence between groups (i.e., Order A and Order B). Participants were informed that the study goal was to investigate the efficacy of two forms of upper-extremity rehabilitation and were actively counseled to not discuss the specific therapeutic activities with study personnel other than the treatment physical therapist.

\section{Therapeutic interventions}

Algorithms for both the FTP and HYBRID interventions have been described in detail elsewhere [21]. Briefly, treatments were administered on alternate days (i.e.,
Monday, Wednesday, Friday) at the same time of day. Individual sessions were 75 minutes in duration and initiated with 10-15 minutes of stretching and passive range of motion.

\section{Functional task practice}

The control intervention involved functional task practice structured according to principles of motor learning [28] and utilized a progression of six therapeutic goals and nine activity categories. Specific tasks, chosen from the activity categories, were practiced on a structured rotation within the framework of the current therapeutic goal. Each of the six treatment goals was addressed for two sessions and treatment progressed to the next therapeutic goal independent of whether mastery of the current goal had been achieved. A variety of therapeutic tasks were developed for each of the nine activity categories (Figure 3), which were identified for individual participants on the basis of functional level, his/her personal goals and needs. Within each session the time devoted to each activity category was held constant at 10 minutes. Thus, individual sessions involved tasks from six activity categories. Each of the nine activity categories was addressed twice per week. Our approach: i) allowed for structure and repeatability across multiple participants in a three-year intervention study, ii) afforded flexibility to accommodate participants presenting with varied hemiparetic severity and functional deficits, and iii) allowed the therapist to tailor intervention using patient-centered goals [29].

\section{HYBRID intervention}

The experimental intervention combined power training with FTP. Each treatment session divided time between upper-extremity power training (35 minutes) and FTP (25-30 minutes). The abbreviated FTP component addressed six of the nine activity categories, which were selected on the basis of the participant's abilities and goals. Each individual session involved practice of four activity categories for seven minutes each. Power training involved four reciprocal upper-limb movements: shoulder abduction/adduction, shoulder flexion/extension, shoulder external/internal rotation and transverse plane elbow flexion/extension and was delivered using a Biodex System 3.0 Pro dynamometer ${ }^{\mathrm{a}}$. Custom attachments, designed to accommodate hand and wrist weakness, were used to enable hemiparetic participants to engage the dynamometer without grasping and to optimize positioning for performance through a full range of motion for each joint (Figure 3). Where necessary, the attachments were counterbalanced to minimize the effect of lifting the weight of the attachment against gravity. Each power training session involved three sets of 10 repetitions of each movement [31]. The first set 


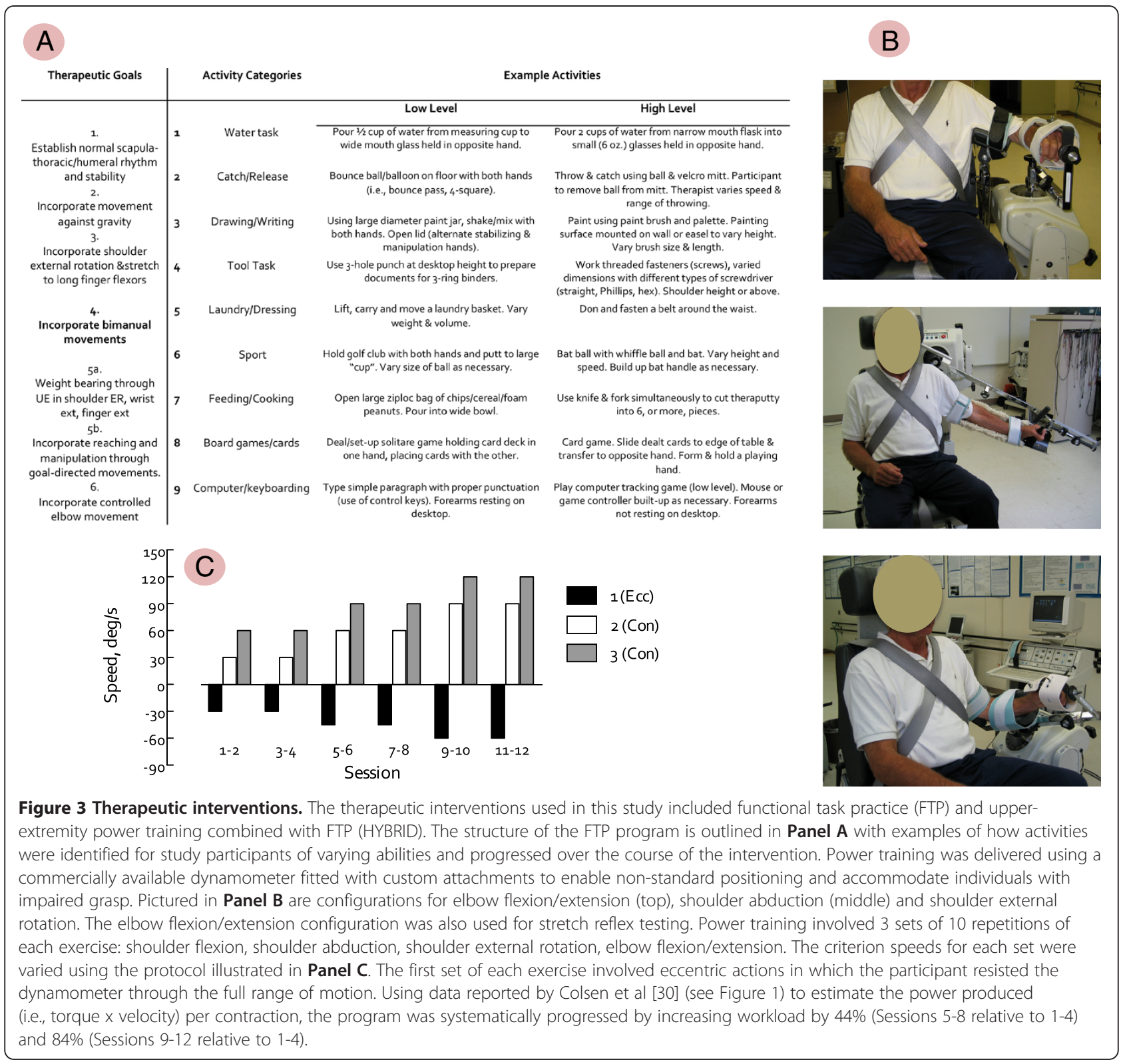

was eccentric (e.g., resisting an externally imposed load) and the second two sets were concentric, delivered at different criterion speeds. The dynamometer was controlled in isokinetic mode (i.e., constrained to pre-set speed). Over the course of treatment, movement speeds were advanced in $30 \%$ s increments in concentric sets (i.e., from $30-120 \% / \mathrm{s}$ ) and $15 \%$ s increments in eccentric sets (i.e., from $30-75^{\circ} / \mathrm{s}$ ) (Figure 3). Power training targeted proximal joints (e.g., shoulder and elbow).

\section{Participant compliance}

All treatment sessions were completed within the timeframe of the study design. Several factors specific to our setting enabled 100\% compliance with the intervention protocols. First, this study was conducted in a free standing rehabilitation research center where study personnel were tasked to project activities rather than routine clinical care. If a participant was unable to attend a session, makeup sessions were scheduled as soon as possible and, only if necessary, on an adjacent day. This measure was taken to assure delivery of the requisite number of treatments in the timeframe specified by the study protocol. The costs of study personnel and participant transportation were underwritten by grant support, thus the therapeutic intervention was delivered at no cost to the participant or his/her insurance provider. In exchange, participants agreed to all intervention sessions and return for follow up evaluations. 


\section{Assessment battery}

A comprehensive battery of clinical and neuromechanical assessments was administered by blinded evaluators at five times across the study: baseline, following each treatment block, following the washout period and at six months post-intervention. Stretch reflex responses were assessed from only the first treatment block and the washout period.

\section{Clinical assessment}

Clinical outcomes were assessed using tools for which validity and reliability have previously been established in individuals post-stroke. Because the purpose of this investigation was to demonstrate treatment efficacy [32], these focused on assessments representing the body structure/ function and activity levels of the International Classification of Functioning, Disability and Health [33] and included: the upper-extremity portion of the Fugl-Meyer motor assessment [27], the Ashworth Scale [34,35] the Wolf Motor Function Test-Functional Abilities Scale (WMFT-FAS) [36-38], and the Functional Independence Measure (FIM) [39]. Self-report questionnaires probing participation and self-efficacy are more appropriately used in later stage clinical investigation of treatment effectiveness [32]. The WMFT-FAS [37,38] served as the primary outcome.

\section{Neuromechanical assessment}

Joint torques were obtained from the dynamometer during elbow flexion (EF) and extension (EE), shoulder flexion (SF), abduction (S'Abd) and external rotation ( $\left.\mathrm{S}^{\prime} \mathrm{ER}\right)$ in the following four conditions: isometric (MVIC), and concentric actions at 30,75 and $120 \%$ s at each of the five assessments. Neuromotor activation was assessed using surface electromyography recorded from eight upper-extremity muscles (biceps brachii, triceps brachii, anterior/middle/posterior deltoid, infraspinatus, brachioradialis, and pectoralis major) using active, pre-amplified surface electrodes $(17 \mathrm{~mm}$ inter-electrode distance). To mitigate the effects of inter-individual variability of electrode placement, subcutaneous adipose tissue thickness and other sources of variability, EMG electrode were placed using the convention of Delagi [40], referenced to anatomical landmarks, by only one investigator. Analog signals (i.e., torque and position) were sampled directly from the dynamometer concurrently with EMG at $2 \mathrm{kHz}$ using custom-written software and written directly to disk for offline analysis. Reliability of neuromechanical measures in this study population has been established in our laboratory $[7,41,42]$.

\section{Stretch reflexes}

Stretch reflex responses were elicited using passive rampand-hold elbow extensions applied using the dynamometer
[43]. The experimental configuration is illustrated in Figure 3 (Panel B, top). Surface EMG was recorded from the brachioradialis, biceps brachii, and triceps brachii (long head) muscles using pre-amplified electrodes ${ }^{\mathrm{b}}$ (MA-311). Analog position and torque signals were sampled directly from the dynamometer at $2 \mathrm{kHz}$ written directly to disk for offline analysis.

For each test session, participants were seated in the dynamometer chair with the back angled at $85^{\circ}$, the trunk stabilized using waist and trunk straps, and the feet supported using the leg rest. The hemiparetic arm was positioned with the shoulder in $70-80^{\circ}$ abduction, and $5-10^{\circ}$ forward flexion with the medial epicondyle of the humerus aligned with the dynamometer rotational axis. The arm was stabilized using an adjustable support to balance the weight of the limb and eliminate excess shoulder rotation during elbow flexion and extension. The wrist and hand were positioned in pronation using a pre-fabricated wrist splint and straps added to the standard dynamometer wrist attachment. Passive elbow extensions covered a $100^{\circ}$ range ending at the participant's full anatomical range of motion. The anatomical position was determined using a handheld goniometer and reported in degrees of elbow flexion (i.e., full extension $=0^{\circ}$ ). Anatomical angles were used to report subject-specific joint angles for the onset of reflex activity. The dynamometer angle corresponding with $90^{\circ}$ elbow flexion was recorded in A/D units and used to reproduce the anatomical $90^{\circ}$ elbow flexion position in subsequent evaluation sessions. Positioning was replicated at each session by recording the dynamometer and chair position settings for each participant.

Velocity-dependent reflex responses were tested by operating the dynamometer in passive mode under panel control. Each trial was comprised of four phases: i) 10 second static hold in elbow flexion; ii) passive elbow extension at criterion speed; iii) 5 second static hold in full extension; iv) passive return to elbow flexion at $30 \%$ s. During all movement phases, participants were instructed to relax as the limb was moved through the full range of elbow motion by the dynamometer. Torque, position and EMG data were collected before and during passive elbow extension stretches. Passive stretches were delivered at five criterion speeds (i.e., $60^{\circ} / \mathrm{s}, 90^{\circ} / \mathrm{s}, 120^{\circ} / \mathrm{s}, 150^{\circ} / \mathrm{s}, 180^{\circ} / \mathrm{s}$ ). After every third trial the test speed was incremented by $30 \%$ s to obtain three trials at each criterion. Two additional trials were obtained at $10 \%$ s to quantify passive joint torques. The reliability of both EMG and torque responses has been established for ramp-and-hold stretches obtained using this paradigm and range of speeds [41].

\section{Data analysis}

Neuromechanical assessments

Torque, position and EMG were analyzed using MATLAB $(\text { Version } 6.5 .0)^{\mathrm{d}}$. The torque and position signals were 
digitally lowpass filtered (20 Hz cutoff, zero-phase shift, $1^{\text {st }}$-order Butterworth filter). Velocity was determined by calculating the derivative of the filtered position signal. This calculated signal was subsequently digitally lowpass filtered at $20 \mathrm{~Hz}$. Maximal isometric joint torque (MVIC), agonist EMG at MVIC, and peak power were evaluated for the five movements listed above. Muscle length and joint position effects were controlled by defining a $15^{\circ}$ window centered at the optimal position ${ }^{\mathrm{e}}$ for each joint action. Isometric, concentric and eccentric torque, velocity and EMG were evaluated over this range. Power was calculated as the product of torque and velocity within this window. Peak power was extracted from the condition (i.e., 30,75 or $120 \%$ s) producing the highest value. Neuromuscular activation was evaluated by determining the EMG amplitude during MVIC. Raw EMG signals were gain-corrected, filtered (10-200 $\mathrm{Hz}$ bandpass, zero-phase shift, $1^{\text {st }}$-order Butterworth filter), and the RMS average calculated over the same position window as torque [6].

\section{Stretch reflexes}

The slow $(10 \%)$ passive torque response at each position was subtracted from the torque measured during stretches imposed at all speeds. Raw EMG signals were gain-corrected, filtered $(200 \mathrm{~Hz}$ lowpass, zero-phase shift, $1^{\text {st }}$ order Butterworth filter), demeaned and rectified. EMG was evaluated as the mean amplitude calculated over a $100 \mathrm{~ms}$ sliding window. For each trial, EMG was defined as active when the mean amplitude exceeded threshold (i.e., mean baseline, resting EMG plus 2.5 standard deviations [43] (Figure 4). To assure analysis of only passive stretches, trials with EMG activity present within $200 \mathrm{~ms}$ of movement onset were not analyzed.

The processed EMG data were used to obtain three criteria (illustrated in Figure 4) indicative of stretch reflex modulation:

1. EMG Burst Duration - percentage of the movement time (MT) during which EMG activity was present.

2. Position Threshold - joint angle, expressed in degrees of elbow flexion, at which EMG activity was first identified. If the EMG activity was absent for the entire imposed stretch, the position threshold was reported as $0^{\circ}$, corresponding to full extension.

3. Burst Amount - mean EMG amplitude when the muscle was determined to be active minus baseline resting activity.

4. Torque - average torque calculated over a $100 \mathrm{~ms}$ window centered at 40 degrees of elbow flexion. Only trials in which the torque was $0.05 \mathrm{Nm}$ greater than the slow passive torque (i.e., $10 \%$ s) were considered in the analysis. Using this criterion, valid torques were not obtained at any speed for one participant at the post-treatment evaluation, and two participants at the retention period, thus their data were excluded from this analysis reducing the data set to 16 of 19 participants.

\section{Statistical analysis \\ Clinical assessments}

Data were tested for normality using the D'Agostino \& Pearson Omnibus normality test and found to be normally distributed. Baseline equivalence between treatment orders was confirmed using unpaired t-tests for between-group comparisons of clinical data. Three sets of comparisons were performed: the first two evaluated intervention-related changes between FTP and HYBRID, while the third tested for an effect of treatment order. The full set of comparisons included:

1) the primary treatment effect - evaluated by comparing change scores following treatment block1 (i.e., FTP vs. HYBRID);

2) block, or period, effect - evaluated by comparing the difference in magnitude of block1 and block2 change scores calculated within each treatment order (i.e., Order A: (HYBRID - FTP) vs. Order B: (FTP HYBRID). Equivalent effects between interventions would yield a non-significant difference between treatment orders because differences in change scores between blocks would reveal a potential period effect. However, a significant, non-zero difference between orders A and B would occur in the presence of differential treatment effects for FTP and HYBRID [26].

3) The effect of treatment order - evaluated by comparing the overall change between baseline and completion of the second treatment block (i.e., sum of block1 and block2 change scores for each group (Order A vs. Order B).

Retention effects were assessed as differences between baseline and 6-month follow up. Missing data that resulted if participants were lost to follow up were treated using the last value carried forward [44].

To determine the scale of intervention-related differences, effect sizes were calculated using the difference between the means of the two interventions (FTP vs. HYBRID) divided by the common standard deviation (SD) at study baseline. Effect sizes were interpreted using benchmarks established by Cohen [45] where 0.2 is indicative of small, 0.5 medium, and $\geq 0.8$ large effect sizes.

The primary outcome (WMFT-FAS) was evaluated using independent samples t-tests to test the hypothesis that improvements following HYBRID would exceed those in response to FTP. 


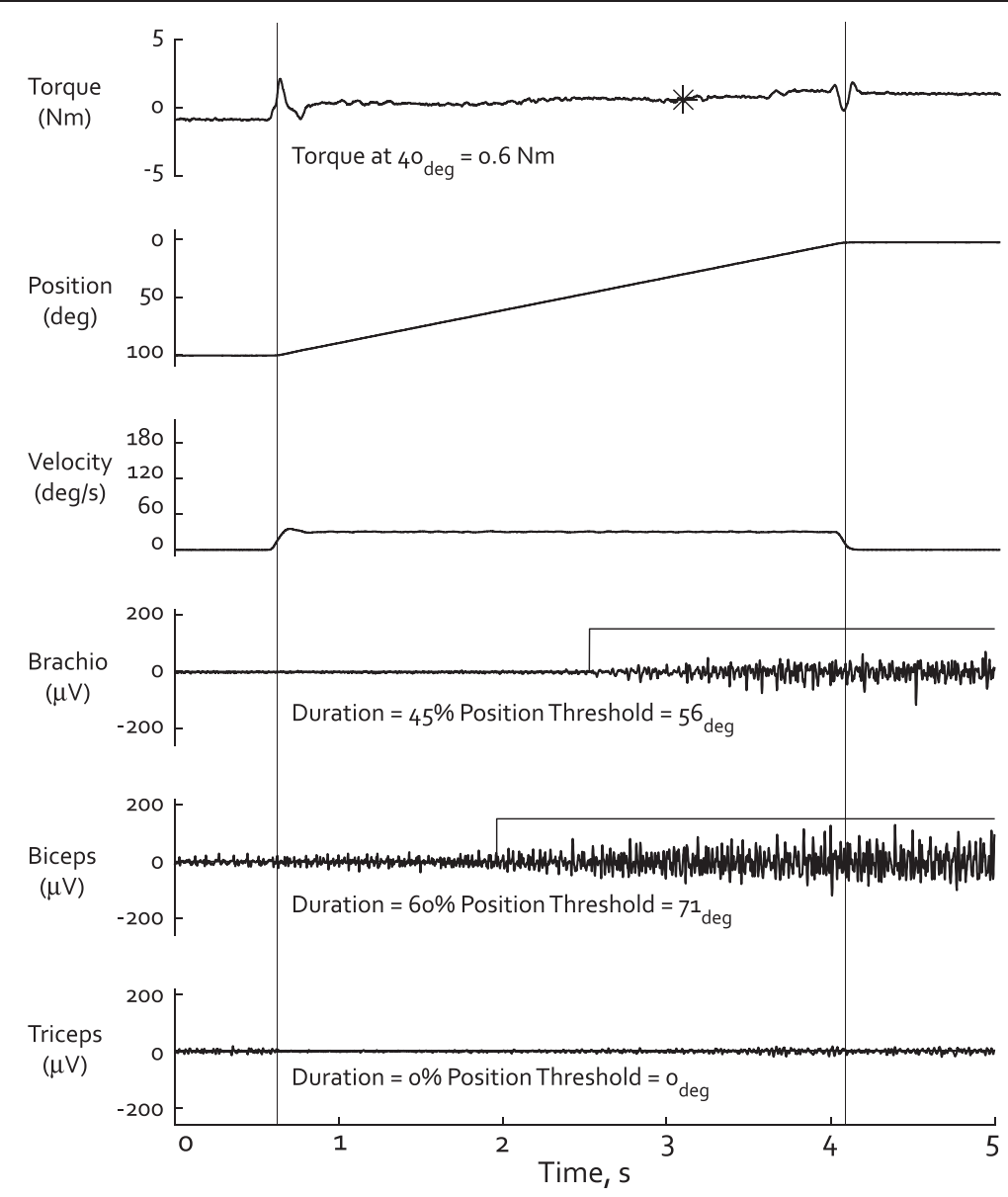

Figure 4 Elbow stretch reflex responses. Exemplary data from passive elbow stretches as described in methods. Top three panels illustrate torque, position and velocity, respectively, and bottom three panels, EMG from brachioradialis, biceps brachii, and triceps brachii, respectively. Vertical cursors mark trial onset and offset. Position reflects flexion at start $\left(100^{\circ}\right)$ and extension at end $\left(0^{\circ}\right)$. Velocity is constant over the period of passive stretch. Passive torque was measured at $40^{\circ}$ elbow flexion for all individuals (noted by asterisk on top panel), which falls in the mid-range of joint position. Horizontal lines overlaid on brachioradialis and biceps EMG denote muscle activity "on" period. The position onset and duration of EMG activity were determined for each individual trial. Improvement in reflex modulation (e.g., reduced hyperreflexia) would reveal a reflex position threshold in a more extended position corresponding with lower values.

Secondary clinical outcomes were evaluated by establishing the minimally important difference (MID) for each measure and testing for sample proportions achieving the MID. The MID is a distribution-based measurement approach [46] for determining clinically relevant change, defined as one-half of the standard deviation observed at baseline [47]. Differences between treatments (i.e., FTP vs. HYBRID) were probed using Chi-square analysis, and where appropriate Fisher's Exact test, to test for the proportion of the study sample that produced the relevant MID.

\section{Neuromechanical assessments}

Torque and EMG data were tested using mixed-model repeated-measures ANOVA (RM-ANOVA) with main effects of treatment order (group), treatment and joint action. Tukey's HSD test was used for post-hoc testing to identify the location of significant effects.

\section{Stretch reflex assessments}

To account for inter-subject variability all measures were evaluated as change scores relative to baseline. The magnitude of change in EMG responses to imposed stretch was assessed for both significant within-group changes relative to baseline and for between-group differences. Within each group, single factor t-tests were used to determine if the mean change, pooled across speeds, differed significantly from no change. Between-group differences were assessed using RM-ANOVA.

Statistical analysis was performed using SAS Release 6.12 (reflex data) or JMP (Version 9.0) ${ }^{\mathrm{f}}$. Unless otherwise specified, statistical significance was established as $p<0.05$. 


\section{Results}

\section{Clinical assessments}

\section{Primary outcome}

Our primary aim was to determine whether power training contributes to functional improvements in the hemiparetic upper-extremity. For the primary outcome (WMFT-FAS), improvements significantly different from zero were revealed following treatment block1 following both FTP and HYBRID $(\mathrm{p}<.05)$. These differences were significantly greater following HYBRID (mean $0.34 \pm 0.06$ (S.E.)) as compared to FTP (mean $0.17 \pm 0.06($ S.E. $))(p=.03)$. Figure 5, Panel A). Testing for a period effect revealed greater improvements following HYBRID vs. FTP $(\mathrm{p}=.02)$ (Figure 5, Panel B) regardless of where they occurred in the treatment order $(\mathrm{p}=.02)$. Overall differences due to treatment order were not revealed (e.g., Order A, FTP-first (mean $0.29 \pm 0.09$ (S.E.)) vs. Order B, HYBRID-first (mean $0.32 \pm 0.10$ (S.E.)), $p=.43$ ) (Figure 5, Panel C). FAS change scores improved further (mean increase: $0.09 \pm .04 \quad$ (S.E.) points) during the 6-month follow up period. While the magnitude of change was small, this improvement was significantly different from zero $(p=.03)$, indicating both retention of treatment effects and advancement of these functional improvements over the 6-month follow up interval. Differences between Order A and Order B were not revealed at 6-month follow up $(p>.05)$.

\section{Secondary outcomes}

Improvements were detected in both the total and shoulder-elbow portions of the upper-extremity FuglMeyer score, however no intervention-related differences were revealed in the proportion of participants who achieved the MID immediately post-treatment (Table 2). At 6-months, the MID for the shoulder-elbow sub-score was achieved by $53 \%$ of all participants $(p=.04)$ indicating that treatment-related effects were both retained and advanced during the retention period. No significant changes were revealed on the combined shoulder-elbow Ashworth score at either the post-intervention or 6-month retention evaluation $(\mathrm{p}>.05)$. A significantly greater proportion of participants (51\% vs. $39 \%$ ) produced the MID of two points or more on the FIM following HYBRID $(p=.05)$. These positive changes were observed in $69 \%$ of participants at 6 -months $(p=.05)$. Mean change scores calculated for each of the clinical assessments are reported in Table 2.

\section{Neuromechanical assessments Isometric joint torque}

The magnitude of change in isometric joint torques was similar among the five joint actions tested $(p=.53)$ (range $11.03 \%( \pm 9.6)-28.4 \%( \pm 10.0))$. A significant effect of treatment revealed greater increases in isometric joint torque following HYBRID $(28.17 \%( \pm 3.9))$ than FTP $(12.5 \%( \pm 4.2)) \quad(p<.0001)$. Changes in isometric joint torque relative to baseline are illustrated by treatment order and individual joint action in Figure 6, Panel A. No interactions of group (treatment order) or joint action were revealed $(p>.05)$.

\section{EMG at maximal voluntary isometric contraction}

Similar to effects reported for isometric joint torque, the magnitude of change in agonist muscle EMG during MVIC was similar among the joint actions tested $(p>.05)$ (range: $10.79 \%( \pm 5.5)-36.63 \%( \pm 4.7)$ ). A significant effect of treatment revealed greater increases following HYBRID $(24.74 \%( \pm 6.2))$ as compared to FTP $(7.34 \%( \pm 7.4))(p<.0001)$. Changes in EMG at MVIC, relative to baseline, are illustrated by treatment order and joint action in Figure 6, Panel B. No interactions of group (treatment order) or joint action were revealed $(p>.05)$.

\section{Joint power}

Changes in peak power for each movement paralleled effects revealed in isometric joint torque and EMG at MVIC,
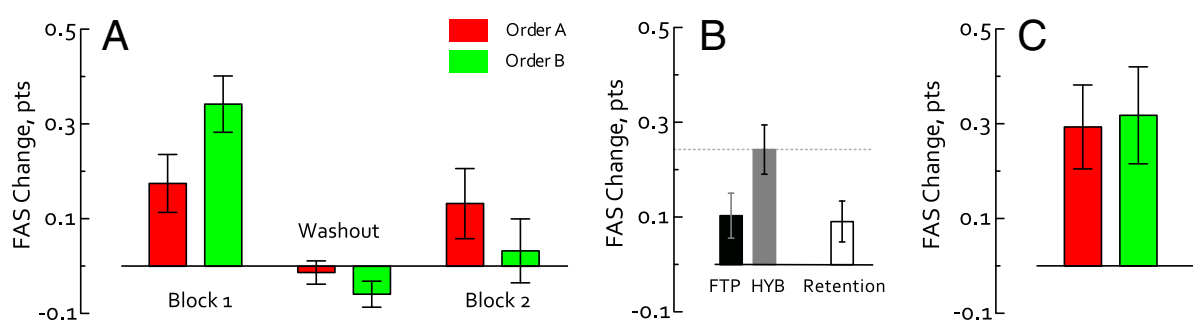

Figure 5 WMFT FAS change scores. The primary outcome was analyzed by evaluating change scores (post-pre). Panel A. FAS change scores plotted by treatment block. Participants in treatment Order A (red) received FTP first. Improvements in the FAS score were similar between blocks 1 and 2. Participants in treatment Order B (green) received HYBRID first. Improvements in the FAS score were larger in Block 1 (HYBRID) than Block 2 (FTP). Negligible changes were detected following the washout period. Panel B. Change scores pooled across treatment blocks for FTP and HYBRID reveal significantly greater improvements following HYBRID (gray) vs. FTP (black). Panel C. Overall differences were not revealed between treatment orders (Order A-red, Order B-green) following both treatment blocks (i.e., post-block2 - baseline) and the intervening washout period. At the 6-month follow up, additional, small changes in FAS scores were detected (Panel B, white bar); effects were similar between Order A and Order B. 


\begin{tabular}{|c|c|c|c|c|}
\hline \multirow{2}{*}{$\begin{array}{l}\text { Intervention effects } \\
\text { Measure }\end{array}$} & \multirow[b]{2}{*}{ FTP } & \multirow[b]{2}{*}{ HYBRID } & \multirow[b]{2}{*}{ E.S. } & \\
\hline & & & & \\
\hline \multicolumn{5}{|l|}{ Primary Outcome } \\
\hline \multirow{2}{*}{$\begin{array}{l}\text { Wolf Motor Function Test } \\
\text { (FAS, Range 0-5 pts) }\end{array}$} & 0.10 & 0.24 & 0.50 & $*$ \\
\hline & (SE 0.05) & (SE 0.05) & & \\
\hline \multicolumn{5}{|l|}{ Secondary Outcomes } \\
\hline $\begin{array}{l}\text { UE Fugl-Meyer Motor Score } \\
\text { (66 pts) }\end{array}$ & 2.94 & 2.89 & 0.2 & n.s. \\
\hline$M I D \geq 5$ & (SE 0.72) & (SE 0.79) & & \\
\hline $\begin{array}{l}\text { Fugl-Meyer Shoulder-Elbow Score } \\
\text { (30 pts) }\end{array}$ & 1.83 & 0.79 & 0.87 & n.s. \\
\hline$M I D \geq 3$ & (SE 0.40) & (SE 0.38) & & \\
\hline Ashworth Scale (shoulder + elbow, 8 pts) & -0.16 & -0.11 & 0.07 & n.s. \\
\hline $\mathrm{MID} \geq 1$ & (SE 0.24) & (SE 0.24) & & \\
\hline $\begin{array}{l}\text { Functional Independence Measure } \\
\text { (91 pts) }\end{array}$ & 0.67 & 2.21 & 0.81 & * \\
\hline$M I D \geq 2$ & E 0.63) & E 0.61) & & \\
\hline
\end{tabular}

Retention Effects (6-month Follow Up)

\begin{tabular}{|c|c|c|c|}
\hline Measure & & & \\
\hline Primary Outcome & & & \\
\hline Wolf Motor Function Test & 0.10 & 0.65 & * \\
\hline (FAS, Range 0-5 pts) & (SE 0.05) & & \\
\hline Secondary Outcomes & & & \\
\hline UE Fugl-Meyer Motor Score (66 pts) & 7.2 & 3.09 & * \\
\hline$M I D \geq 5$ & (SE 1.55) & & \\
\hline $\begin{array}{l}\text { Fugl-Meyer Shoulder-Elbow Score } \\
\text { (30 pts) }\end{array}$ & 2.82 & 2.35 & * \\
\hline$M I D \geq 3$ & (SE 0.51) & & \\
\hline Ashworth Scale (shoulder + elbow, 8 pts) & -0.21 & 0.28 & n.s. \\
\hline$M I D \geq 1$ & (SE 0.24) & & \\
\hline $\begin{array}{l}\text { Functional Independence Measure } \\
\text { (91 pts) }\end{array}$ & 3.6 & 1.89 & $*$ \\
\hline$M I D \geq 2$ & (SE 1.21) & & \\
\hline
\end{tabular}

Data are presented as mean (SE) change scores and reflect mean changes due to the treatment specified (i.e, Post-Pre for block involving FTP or HYBRID). Retention effects at 6-month follow up reflect change scores from the follow up period (i.e., 6-months-post-treatment).

Unless otherwise noted, statistical significance was set at $p<.05$ (denoted as ${ }^{*}$ ) and reflects significant differences between treatments. Secondary outcomes were tested for differences in the proportion of participants demonstrating an MID post-treatment. Effect sizes (ES) reflect between-group differences. 6month follow up data reflect retention and/or advancement of primary treatment effects. Due to the cross-over design effects reflect overall differences relative to baseline.

described above. As would be expected, significant differences in peak power were revealed between joint actions (shoulder external rotation $(726.5 \mathrm{~W})<$ elbow extension $(969.7 \quad \mathrm{~W})=$ shoulder $\quad$ abduction $(1109.3 \mathrm{~W})=$ shoulder flexion $(1162.0 \mathrm{~W})<$ elbow flexion $(1688.7 \mathrm{~W}))(p<.0001)$.

A significant effect of treatment revealed markedly greater increases in joint power following HYBRID (36.66\%
$( \pm 11.6))$ as compared to FTP $(-7.86 \%( \pm 3.5))(p<.0001)$. Changes in joint power relative to baseline are illustrated by treatment order and individual joint action in Figure 6, Panel C. Negative changes, indicating loss of joint power following FTP, result from small changes revealed in treatment Order A (mean 9.22\% ( \pm 2.6$)$ ) combined with relative loss of power revealed in treatment Order B $(-19.57 \%( \pm 8.6))$ when FTP was the second intervention. Importantly, for treatment Order B joint power remained elevated relative to baseline $(24.65 \%( \pm 4.3))$ following FTP. No interaction effects of group or treatment and movement were revealed.

Following completion of both intervention blocks (e.g., Session 4), joint power was significantly increased relative to baseline with similar improvements revealed in both treatment orders (Order A: $31.06 \%( \pm 9.1)$, Order B: $24.65 \%( \pm 4.3))$. At the 6-month follow up evaluation (e.g., Session 5) increased joint power was retained in both groups (Order A: $20.24 \%$ ( \pm 6.4 ), Order B: $25.36 \%$ $( \pm 8.0)$ ). The magnitude of changes in joint power following HYBRID did not differ statistically between Order A $(30.84 \%( \pm 9.8))$ and Order B $(42.48 \%( \pm 9.1))(p>.05)$, thus revealing the specific effect of the HYBRID intervention rather than generalized exposure to therapeutic intervention. Overall treatment and retention effects are illustrated in Figure 7.

\section{Stretch reflexes}

Data were obtained from only the first block of the crossover, thus results reflect effects of only a single intervention (i.e., FTP or HYBRID). Brachioradialis responses demonstrated similar patterns at reduced magnitude and triceps responses were negligible. Results and discussion presented here thus focus on the biceps brachii responses. Usable data were not available all participants for all evaluations, thus the number included is stated for each analysis.

Adaptations in biceps stretch reflex activity were revealed as mean negative change in response to passive elbow extensions as measured by EMG variables burst duration, position threshold and burst intensity indicating: shorter burst duration, reflex onset at a more extended position and reduced EMG intensity, respectively. Changes observed following intervention are illustrated in Figure 8.

\section{Burst duration}

Following intervention, the mean duration of biceps activity was reduced following both FTP and HYBRID, although this change differed significantly from zero only following HYBRID $(p=.03)$. Following FTP, only $4 / 6$ participants demonstrated reduced burst duration (mean change - $7.6 \%$ MT (SE 2.9)), which did not differ statistically from zero $(p>.10)$. In contrast, following HYBRID 8/9 participants revealed a significantly reduced burst duration that averaged 


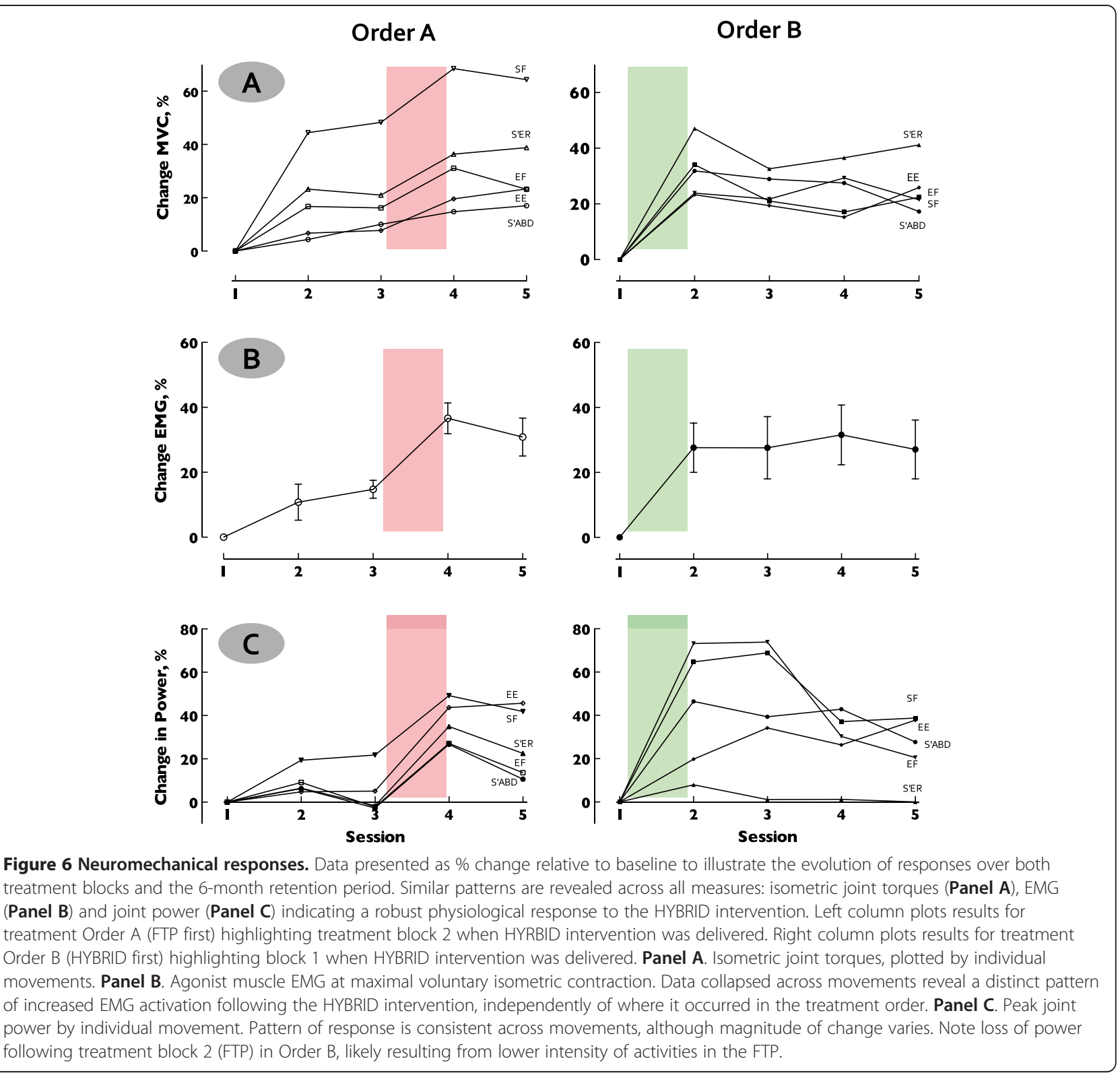

-12.5\% (SE 1.5) MT across speeds. At retention, 3/7 FTP participants and 6/9 HYBRID participants maintained this change to produce mean group changes of $-0.2 \%$ MT (SE 2.3) $(p>.10)$ and $-10.8 \%$ MT (SE 1.6) $(p=.06)$, respectively. Group data for each speed and evaluation are presented in Figure 8, Panel A.

RM-ANOVA was used to test for effects at each criterion speed. When data from all tested criterion speeds (i.e., $60^{\circ} / \mathrm{s}-180^{\circ} / \mathrm{s}$ ) were included, between-group differences failed to reach statistical significance following the retention period. However, the results suggested the presence of an interaction between the group and velocity factors that approached statistical significance $\left(\mathrm{F}_{(4,54)}=2.15\right.$, $p=.087)$. Coupled with our prior investigation that revealed greater stability of reflex responses at higher speeds of stretch [41], this observation motivated a secondary analysis. Responses at criterion speeds $\geq 120 \%$ s revealed a greater reduction in burst duration in response to HYBRID which reached statistical significance $\left(\mathrm{F}_{(1,14)}=4.74, p<.05\right)$ following the retention period.

\section{Position threshold}

The pattern of changes in the position threshold was similar to that observed in the burst duration. Both groups demonstrated improvements, but mean differences post-intervention reached statistical significance and were retained only following HYBRID. Negative change scores in position threshold indicate later onset 


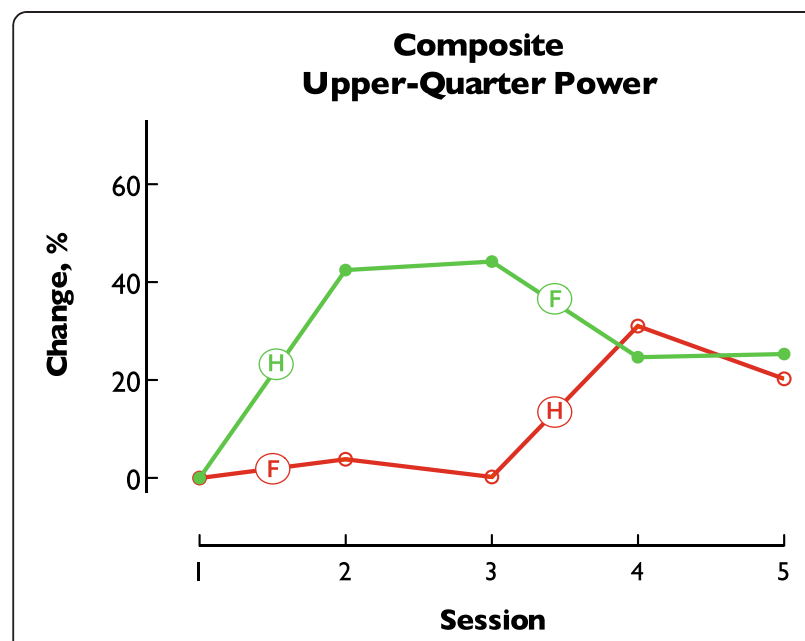

Figure 7 Composite Upper-quarter joint power. Peak power from all movements was collapsed within each treatment order (Order A-Red, Order B-Green) creating a composite representative of upper-quarter performance. Data are expressed as \% change relative to baseline and demonstrate the evolution of response over all phases of the study. Labels note relevant treatment (F: FTP, H: HYBRID). Of note, the magnitude of improvements in response to HYBRID was similar regardless of when the HYBRID intervention was delivered. This result illustrates the strength of using a crossover design to differentiate treatment effects. Overall improvements following both treatment blocks (Session 4) reveal similar changes relative to baseline. Note that increased upper-quarter power is similar between Sessions 4 and 5 indicating retention of improvements at 6-months post-intervention.

of biceps EMG activity, at a more extended position. Post-intervention, 4/6 FTP participants and 8/9 HYBRID participants demonstrated a decreased position threshold at most speeds. Following the retention period, only 3/7 FTP whereas 8/9 HYBRID participants demonstrated this improvement (Figure 8, Panel B). Collapsed across speeds the mean change following FTP was -7.8 degrees (SE 4.6) and -1.7 degrees (SE 2.2) postintervention and post-retention, respectively. Neither change differed from zero $(p>.10)$. Following HYBRID, corresponding change scores reached statistical significance and averaged -16.5 degrees (SE 1.9) postintervention and -15.8 degrees (SE 1.8) post-retention ( $p=.02$ after both periods).

Consistent with the results for burst duration, when data from all speeds were tested using RMANOVA, significant between-group differences were not revealed. However, analysis of this variable also suggested an interaction effect of group and velocity $\left(\mathrm{F}_{(4,54)}=2.53, p=.051\right)$. Secondary analysis of speeds $\geq 120 \%$ s revealed greater changes in the position threshold following HYBRID than FTP that reached statistical significance following the retention period $\left(\mathrm{F}_{(1,14)}=6.03, p<.05\right)$.

\section{Burst amount}

As with the other parameters presented, negative changes in burst intensity indicate reduced stretchinduced biceps activity and therefore represent improvements (Figure 8, Panel C). The majority of participants demonstrated improvements following intervention (4/6 FTP, 6/9 HYBRID). Collapsed across speeds these improvements represented a mean change of $-0.85 \mathrm{mV}$ (SE 0.22) following FTP and $-0.88 \mathrm{mV}$ (SE 0.22) following HYBRID. Following the retention period, only $3 / 7$ FTP participants demonstrated these improvements with a mean change of $-0.45 \mathrm{mV}$ (SE 0.20). However, 5/9 HYBRID participants retained improvements with a mean change of $-0.78 \mathrm{mV}$ (SE 0.31). While none of these changes differed significantly from zero $(p>.10)$, the pattern revealed is consistent with that observed in the burst duration and position threshold variables, thus these data are included for sake of completeness. Improvements occurred in response to both interventions but at follow up were retained only in individuals who received HYBRID.

\section{Torque responses}

No consistent changes in the passive torque response were revealed following FTP. Collapsed across speeds, mean changes in passive torque following FTP were $-6.9 \%$ (SE 4.7), and -10.1\% (SE 6.4) following intervention and retention, respectively, and failed to reach statistical significance $(p>.10)$. Passive torque was reduced in 4/6 individuals following FTP and 6/7 participants following the retention period. While these proportions suggest greater improvements following the retention period, mean changes at each speed expressed as a percentage of baseline torque (Figure 8, Panel D, left) reveal large variability. In particular, one individual produced large increases in torque.

In contrast, following HYBRID $7 / 8$ participants demonstrated a reduction in the resistance to imposed stretches corresponding to a group mean of $-15.3 \%$ (SE 4.3). This effect also failed to reach statistical significance $(p>.10)$. However, following the retention period, passive torque was reduced in all $7 / 7$ participants. Importantly, not only were the reductions revealed following the HYBRID intervention retained, but the magnitude was greater following the retention period reaching -30.3\% (SE 1.4) which differed significantly from zero $(p<.001)$. Thus, the HYBRID intervention appeared to produce systematic changes in passive torque across speeds (Figure 8 , Panel D, right) of greater magnitude to those detected following FTP. However, due to large inter-subject variability statistically significant differences were revealed only within each group. 

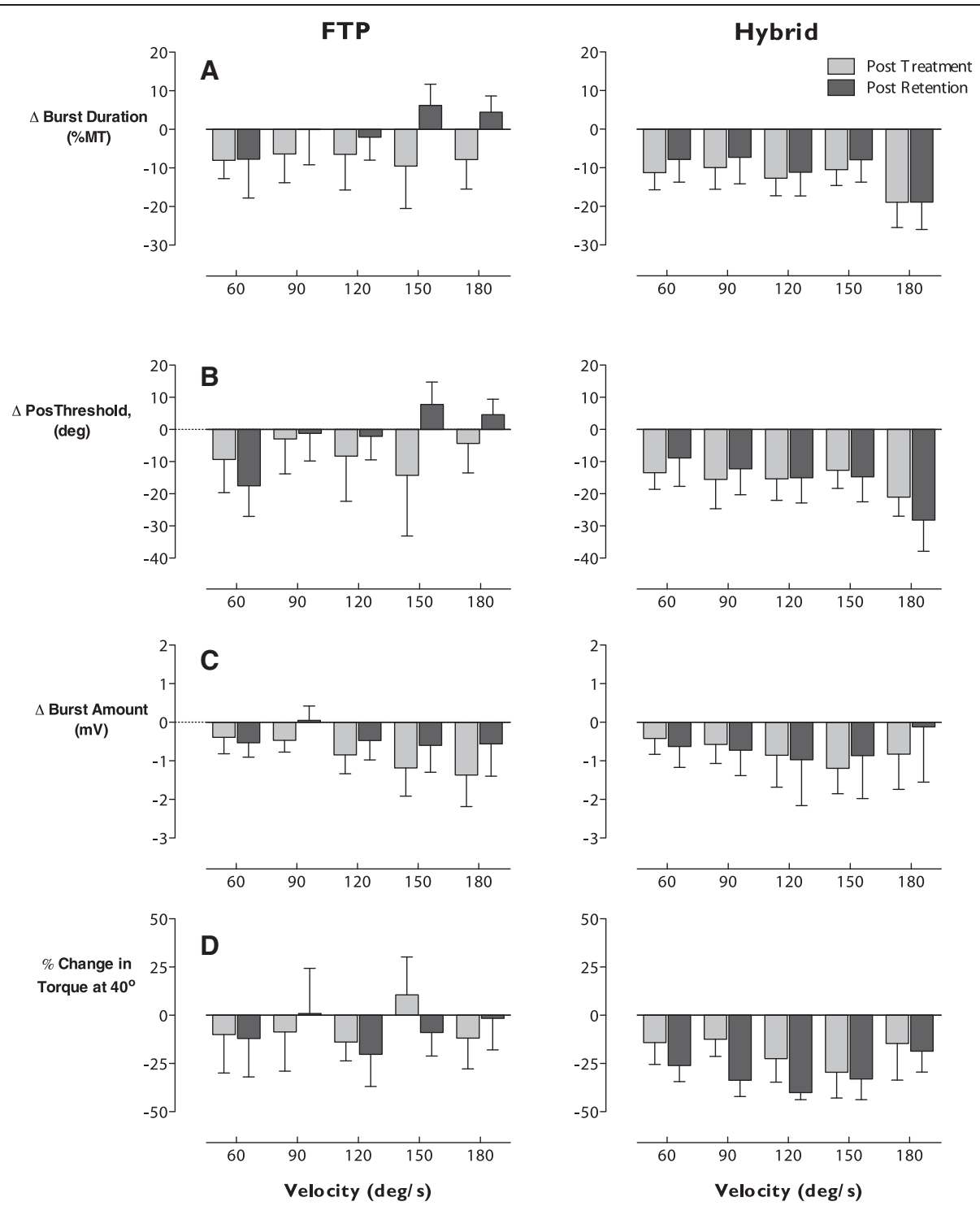

Figure 8 Adaptations in stretch reflex responses. Velocity-dependent responses to passive elbow stretch expressed as change scores relative to baseline for post-treatment (gray) and post-washout (black). Data are presented for the first block of the crossover, thus reflect response to a single treatment, FTP (left column) or HYBRID (right column). Negative values signify improvement (i.e., reduced EMG activity (Panel A), position threshold in greater elbow extension (Panel B), reduced passive torque (Panel D)). Positive values would indicate exacerbation of stretch-induced activity. Systematic, velocity-dependent improvements are revealed across parameters following HYBRID. While some improvements are noted following FTP, these are less consistent and not well retained over the 4-week washout. Results for the burst amount variable (Panel C) did not reach statistical significance, but are included to illustrate the consistent effect. Improvements in passive torque were greater and reached statistical significance following the washout. Taken together these results are consistent with the differential rate of neural (early) and muscular (later) adaptations.

\section{Discussion}

This study investigated the feasibility, safety and efficacy of upper-extremity power training in persons poststroke. Our main finding is that inclusion of power training (i.e., dynamic, high-intensity resistance training) in a program of upper-extremity rehabilitation is feasible, without negative consequences including either musculoskeletal compromise or exacerbation of spasticity. Functional recovery, as documented by the WMFT-
FAS and other clinical indicators, was greater following HYBRID than FTP. Intervention-related effects were both retained and, in some cases, advanced during a 6month retention period. To our knowledge, this is the first study demonstrating advancement of interventionrelated improvements over a 6-month period of no additional intervention.

Several novel aspects of the intervention reported here likely contribute to our positive results: 1) high-intensity 
workloads with progression to advance the challenge over the course of the intervention [48]; 2) dynamic contractions that challenged the impaired nervous system to increase movement speed and muscle power; 3 ) presentation of eccentric contractions which - a) increases the absolute magnitude of the training stimulus, b) involves alternative neural strategies for execution, c) requires force production throughout the full range of motion and therefore facilitate reacquisition of this critical neural mechanism of force production.

\section{Relationship of findings to current research results}

Other studies have compared strengthening and task practice for persons post-stroke in the sub-acute [49] and chronic [50] periods of recovery with conclusions of both favoring functional task practice. Careful examination of the methods and training parameters, however, reveals that the training approach used in the present study differed considerably. Among those previous studies, the first based strengthening on functional activities performed with either increased resistance or repetitions, while the second utilized an independent homebased program of limited scope and intensity. Most notably, therapeutic activities in both studies were not graded relative to maximal capacity and algorithms for progressive challenge of resistance training were not evident. A third study utilized a uniplanar robot to deliver a high volume of resisted upper-extremity movements, all performed in the transverse plane at table top height [51]. Similar to the outcomes of the activity-based functional therapies described above, resisted and nonresisted robotic therapy appeared equally effective. However, the peak resistance level presented in the entire six-week robotic protocol was $28 \mathrm{~N}(\sim 6.3 \#$ or $2.9 \mathrm{~kg})$ and an algorithm for systematic progression of the resistive load was not evident. Using grip force as a proxy for upper-extremity strength, normative values for MVIC grip force average $236 \mathrm{~N}$ and $383 \mathrm{~N}$ for women and men, respectively, aged 60-69 [52] indicating that the resistance used in this robotic study involved only $7-10 \%$ of maximal capacity. These three studies each concluded no benefit of strengthening for improving function in the hemiparetic upper-extremity. Yet, in all three cases the resistance intervention may have lacked sufficient contrast to the alternative task-specific practice approach. More importantly, in all three cases the intensity of the resistance was most likely insufficient to represent an overload stimulus [53], which therefore readily explains the failure to produce meaningful effects on either strength or function. Because the current study involved dynamic contractions, direct comparison to the resistance levels used in the three earlier studies is not possible. As explained in the description of the therapeutic interventions (Figure 3), the training prescription in the current study differed from previously conducted studies in three ways: 1) resistance exercise targeted contractions at specific velocities, 2) intensity of the resistance required a high level of the participant's maximal capacity and 3) work load was systematically progressed over the course of the intervention.

In contrast, a recent study utilized a robotic-type device that offered both static resistance (i.e., isometric) and repetitive arm movements at preset constant velocities (i.e., isovelocity) that required production of a minimum threshold force throughout the full range of motion [54]. Eight weeks of training (24 sessions) using this combination of parameters (i.e., threshold force throughout the movement, dynamic contractions, systematic repetition) in persons six or more months poststroke produced increases in grip and isometric shoulder strength ranging from $22-62 \%$ and modest gains on the UE Fugl-Meyer assessment, both outcomes comparable to those revealed in the present study. Perhaps more remarkable were significant improvements in critical parameters of reaching including: movement speed, time-topeak velocity, minimum jerk and inter-joint coordination suggesting that repetitive training on the basis of key biomechanical parameters facilitates improved coordination of multi-segmental upper-extremity movements.

\section{Does improved strength relate to improved function?}

Weakness has long been recognized as a prominent characteristic of post-stroke hemiparesis, yet the relationship between increased strength and improved function has been elusive. Despite evidence of beneficial effects of strengthening, evidence to support concurrent effects on functional motor performance remains equivocal $[55,56]$. Accordingly, prevailing clinical perspectives assert that remediation of weakness is a problem distinct from restoration of function and task-specific practice is requisite to promote improved functional performance $[49,56]$. Moreover, there is strong evidence to suggest that repetitive task practice drives neural plasticity at the supraspinal level [57,58]. Given these assertions the results of the present study are novel. HYBRID produced significant improvements not only in isometric strength, neuromotor activation and power production, but clinical parameters of impairment and functional activities. To our knowledge, only two other studies [21,23], have reported improvement in upper-extremity function following resistance training. While we recognize that the HYBRID intervention combined functional task practice and power training, the results reveal larger effects on all measures compared to functional task practice alone. Thus, it appears that functional outcomes are improved by directly addressing the weakness component of post-stroke hemiparesis.

The majority of studies pertaining to persons poststroke characterize weakness using isometric force 
measurements and from these data it has been concluded that improved strength does not contribute to improved function. Because functional task performance is dynamic, characterization of muscle performance under dynamic conditions is more relevant to understanding functional motor impairment. Indeed, intervention-related increases in dynamic torque generation have been revealed in conjunction with absence of improvements in isometric force [21]. Power represents the capacity to generate force over time (i.e., in a moving joint [48]). Quantification of a dynamic muscle performance parameter, such as power, may thus reveal the elusive link between strength and enhanced functional performance relevant to profoundly motor compromised populations such as poststroke hemiparesis.

A stronger relationship has been demonstrated between power and function than between strength and function in older adults $[59,60]$. The contribution of neuromotor control mechanisms to this relationship is unmistakable. For example, reduced power production in mobilitylimited elders is strongly associated with the rate of EMG production [61]. Conversely, older adults who maintain competitive fitness for power lifting retain maximal motor unit firing rates at levels comparable to healthy young individuals [62]. High-velocity and/or explosive training increases neuromuscular and mechanical power to a greater extent than strength training and is associated with improved performance on functional tasks $[59,63]$. Leveraging these findings we questioned whether the obvious manifestations of neuromotor impairment following stroke would respond similarly to older adults without neuropathology. Additional work in our laboratory, separate from this current study, has demonstrated that upperextremity power training in isolation (i.e., not combined with FTP) is equally, if not more, effective than FTP for promoting recovery of functional upper-extremity movements [23].

\section{Strength and activation changes}

The early phase (i.e., 2-6 weeks) of resistance training is known to produce neural adaptations which influence the magnitude and organization of motor output (e.g., "central motor drive") and may include: improvements in cortical excitability, alterations in motor unit recruitment threshold, changes in motor unit firing patterns (e.g., increased recruitment, rate coding, presence of doublets, motor unit synchronization, etc.) [64-67] and alteration in the patterns of force production including an increased rate of force production [68]. Both the magnitude and time course of increased isometric strength, EMG at MVIC, and joint power in response to HYBRID are consistent with such neural adaptations [66].

Recent work documents both increased corticospinal excitability and marked reduction of GABA-mediated short intracortical inhibition (SICI) following 4 weeks of dynamic, high-load resistance training [69]. While this work provides clear evidence of functional changes in the strength of corticospinal projections following resistance training, reduced SICI may be more relevant to the current study and individuals post-stroke. Corticomotor drive results from the net balance of excitatory and inhibitory influences integrated by the intra-cortical circuits [70]. Reduced SICI reveals reduced inhibition, resulting from unmasking of silent synapses (e.g., disinhibition) and, potentially, synaptic plasticity at the cortical level $[58,71]$. Excessive inhibition of the ipsilesional hemisphere is recognized following stroke and restoration of the balance of cortical excitability between hemispheres is now acknowledged as a target for motor rehabilitation [72]. This recent demonstration of cortical disinhibition in response to dynamic, high-load resistance training suggests potential mechanisms mediating the positive neuromechanical and functional outcomes demonstrated in the present study, which can be systematically investigated in future research.

\section{High-exertion activity does not exacerbate spasticity}

Our results also reveal concurrent improvements in biceps brachii stretch reflex modulation and upper-extremity functional use in response to HYBRID. While clinical assessment using the Ashworth Scale revealed no significant changes following either FTP or HYBRID, both stretch reflex modulation (e.g., hyperreflexia) and passive torque responses (e.g., hypertonia) were significantly improved following HYBRID. Comparable effects were not revealed following FTP.

We hypothesized that high-intensity activity would not exacerbate spasticity. Unexpectedly, our findings demonstrate that high-intensity motor activity actually induces positive adaptations in reflex modulation that are retained in the absence of additional intervention. Previous work investigating the mechanisms of hyperreflexia has provided evidence for: increased/abnormal motoneuron excitability [73]; increases in activation of dendritic persistent inward currents [74-76]; decreased presynaptic inhibition [77]; diffuse changes at the level of spinal circuitry affecting responses in multiple muscles [78-80], and aberrant depolarizing synaptic drive [81]. Reductions in aberrant activity, including systematic changes in the onset threshold of reflex activity as observed following HYBRID, can thus be considered positive adaptations in the direction of normal stretch reflex activity. The behavioral manifestations of neural recovery undoubtedly involve the integration of adaptations throughout the neuraxis. When studied concurrently with clinical and functional performance, reflex responses provide a means to monitor these multifactorial physiological adaptations. 


\section{Active control}

In the present study the experimental, HYBRID, intervention was compared directly to an active control intervention (FTP). The functional task practice program was developed according to principles guiding current clinical practice [82] and afforded dose-equivalent matching for treatment time, time on task, and practitioner exposure. Repetitive task practice is argued as the intervention approach of choice for driving functional reorganization of the nervous system post-stroke [24,49,56]. While intervention-related effects were indeed observed in response to the control intervention, the experimental intervention produced both larger changes and a larger proportion of participants producing clinically significant improvements. In contrast to many investigations of rehabilitation efficacy $[24,83,84]$, our approach was to determine whether the experimental intervention would produce greater effects than a standardized treatment developed to meet the putative parameters of current clinical practice. In so doing, we anticipated that the control intervention would reveal treatment-related gains.

\section{Crossover design}

Our use of a crossover design enabled us to monitor responses to both interventions in the same individuals strengthening our findings regarding differential treatment effects between HYBRID and FTP. Crossover designs offer two clear advantages. First, the influence of confounding covariates and heterogeneity between individuals is reduced because each participant serves as his/her own control. It can be expected that an intervention will produce large and small responses among individuals and similarly, that individuals may be high and low responders. Thus, the crossover can detect differential responses to therapies, should they exist. Second, optimal crossover designs are statistically efficient, thus require fewer subjects [26].

Crossover studies also present challenges, two of which are the potential of order effects and the potential of carry-over between treatments. It is possible that the order in which treatments are administered will affect the outcome [85]. In the case of rehabilitation, this outcome may be genuine in that one treatment order is more efficacious or may result from a variety of influences. Clinical assessments typically used in rehabilitation are not optimally sensitive or responsive to change and thus are prone to ceiling and floor effects. Compounding these problems of clinical assessment there may be a learning effect or physiological conditioning effect in response to active therapy following a period of relatively sedentary lifestyle. Taken together, these circumstantial influences may contribute to greater responses to the first treatment, regardless of which treatment occurs first. A second concern when using a crossover design is the potential of carry-over between treatments. Carry-over effects are of particular concern in the case of rehabilitation, or exercise, where the intent is to induce persistent changes. In practice, carry-over effects can be avoided with a sufficiently long washout period between treatments. In the worst case, if treatment effects are non-specific and retained through a washout period, a crossover design would yield the obvious result - more therapy is better. In the best case, a crossover design can reveal differential effects of intervention and may suggest order effects that would optimize the ordering of activities in rehabilitation [23]. In the present study, the differential effects of FTP and HYBRID can be appreciated across all levels of measurement, clinical, neuromechanical and neurophysiological. While period effects are suggested in some measures (e.g., Figures 5 \& 6), they were not consistently revealed and thus contrast with our recent work [23]. The interventions in the present study shared common elements (i.e., HYBRID involved an abbreviated program of FTP), thus the distinction of ordering may be less clear than when the interventions are contrasting. Regardless, distinct differences in the magnitude of improvements were revealed favoring the HYBRID intervention, which incorporated power training.

\section{FAS}

Given the underlying rationale of objectively assessing movement function with a standardized battery of timed tasks, one might question the choice of the observational, FAS component of the WMFT. The psychometric properties of the WMFT including validity, reliability and discriminant capacity have been established [38]. Consideration of the FAS may be an underappreciated aspect of this literature. Since early efforts, both validity and reliability of the FAS component have been tested and reported [37]. Furthermore, early stages of the ExCITE trial reported psychometrics of all aspects of the WMFT, including the FAS, across study sites [36]. The FAS is equally reliable as the timed portion, and shows a significant negative correlation with performance time [36]. The fundamental point of both these analyses and inclusion of the FAS as a component of the WMFT is that movement speed and quality of movement are interrelated. Work recently published from our lab [23] used the WMFT to assess recovery of upper-extremity motor function post-stroke. Similar to the current study, we sought to understand the differential effects of two treatment interventions. Of note, the WMFT(time) improved equally in response to both interventions, indicating global improvements in motor function. However, kinematics (3D motion capture) differentiated treatment effects between groups with substantial effect sizes, while effect sizes for WMFT(time) were small to 
negligible for differences between groups [23]. Given that the primary question in the current study was to differentiate treatment effects, we elected to report changes in the FAS score. While observational, the FAS score incorporates features of movement captured quantitatively with kinematics. Perhaps more importantly, it affords a measurement instrument readily available to the practicing clinician.

\section{Limitations}

While results of the present study are encouraging, there are a number of limitations and future investigation is clearly warranted to elaborate these early findings. The small sample size limits both generalizability and the ability to better understand whether differential treatment effects occurred in higher and lower functioning participants. Further, although hand function is clearly a critical element driving use of the upper-extremity, this phase of our investigation targeted the shoulder and elbow for both strengthening and functional effects. Our intention was to determine the feasibility, safety and efficacy of performing such high-intensity activity in persons post-stroke. With these fundamental issues addressed we are able to refine the intervention for future investigation. All treatments were delivered by one physical therapist. Due to the interpersonal nature of rehabilitation practice, it is likely that an element of our results can be attributed to the positive experience participants enjoyed in receiving a substantial bout of oneon-one treatment from a therapist with whom they enjoyed a good rapport. In future work additional personnel will be involved in an effort to generalize our findings.

\section{Conclusions}

This efficacy trial of combined functional task practice and power training produced positive, meaningful effects on both clinical and neuromechanical metrics of upperextremity impairment and function that were both retained and advanced over a 6-month retention period. Importantly, no adverse events were noted and no deleterious consequences, including exacerbation of spasticity, resulted from the high-intensity effort.

\section{Endnotes}

${ }^{a}$ Biodex, Medical Systems, Shirley, New York, 119674704 USA.

${ }^{\mathrm{b}}$ MA-311, Motion Lab Systems, Baton Rouge, LA 70816 USA.

${ }^{\mathrm{c}}$ Keithly Instruments, Inc., Cleveland, OH 44139 USA.

${ }^{\mathrm{d}}$ The Mathworks, Inc., Natick, MA, 07160-2098 USA.

${ }^{\mathrm{e}}$ Elbow flexion: $48-63^{\circ}$, Elbow extension: 67-82 ${ }^{\circ}$, Shoulder flexion: $15-30^{\circ}$, Shoulder abduction: $33-48^{\circ}$, Shoulder external rotation: $3-18^{\circ}$. Positions for optimal torque production were identified during pilot testing.

$$
{ }^{f} \text { SAS Institute, Cary, NC } 27513 \text { USA. }
$$

\section{Abbreviations}

EMG: Electromyography; FTP: Functional task practice; HYBRID: Combined power training and functional task practice; MID: Minimal important difference; MVIC: Maximal voluntary isometric contraction force; WMFT: Wolf Motor Function Test; ANOVA: Analysis of variance; SD: Standard deviation; ES: Effect size; MT: Movement Time.

\section{Competing interests}

The authors declare that they have no competing interests.

\section{Authors' contributions}

CP conceived, designed and executed the study, conducted the statistical analyses and drafted the manuscript; EGC developed data analysis methods, performed data analysis and interpretation and contributed to drafting the manuscript; CAD contributed to data acquisition, data analysis and data interpretation; PSL conceived, designed and executed the study, developed data acquisition methods, participated in data analysis and interpretation. All authors read and approved the final manuscript.

\section{Acknowledgements}

This research was supported by the VA Rehabilitation R\&D Service, Merit Review Project \#B2405R (PSL and CP, Co-PIs) and Research Career Scientist Award \#F7823S (CP).

This work was conducted at the Rehabilitation Research \& Development Center, VA Palo Alto Healthcare System, Palo Alto, CA and served in partial fulfillment of a master's degree by Elizabeth G. Condliffe from the Department of Biomedical Engineering at Boston University. Dr. Condliffe received partial support from a Whitaker Foundation Leadership Award to the Boston University Department of Biomedical Engineering.

We thank the following individuals for their contributions to this project: Sarah Northrop, MPT for her involvement in developing and delivering the treatment protocols; Heather Brown, MSPT, Dhara Kothari, PT, MS and Ruth Yap, MS for conduct of patient assessments, and Dr. Kevin McGill for advice regarding the EMG signal processing and data analysis.

Publication of this article was funded in part by the University of Florida Open Access Publishing Fund.

\section{Author details}

${ }^{1}$ Brain Rehabilitation R\&D Center (151A), Malcolm Randall VA Medical Center, 1601 SW Archer Rd, Gainesville, FL 32608, USA. ²Department of Physical Therapy, University of Florida, Gainesville, FL, USA. ${ }^{3}$ Division of Physical Medicine and Rehabilitation, University of Alberta, Edmonton, AB, Canada. ${ }^{4}$ Department of Biomedical Engineering, University of Alberta, Edmonton, AB, Canada. ${ }^{5}$ Rehabilitation Research Center, VA Palo Alto Health Care System, Palo Alto, CA, USA. ${ }^{6}$ Department of Biomedical Engineering, The Catholic University of America, Washington, DC, USA. 7 Veterans Affairs Medical Center, Washington, DC, USA. ${ }^{8}$ Center for Applied Biomechanics and Rehabilitation Research, National Rehabilitation Hospital, Washington, DC, USA.

Received: 9 June 2012 Accepted: 7 January 2013

Published: 21 January 2013

\section{References}

1. Nakayama H, Jorgensen HS, Raaschou HO, Olsen TS: Recovery of upper extremity function in stroke patients: the Copenhagen Stroke Study. Arch Phys Med Rehabil 1994, 75:394-398.

2. van der Lee JH, Snels IA, Beckerman H, Lankhorst GJ, Wagenaar RC, Bouter LM: Exercise therapy for arm function in stroke patients: a systematic review of randomized controlled trials. Clin Rehabil 2001, 15:20-31.

3. Kautz SA, Brown DA: Relationships between timing of muscle excitation and impaired motor performance during cyclical lower extremity movement in post-stroke hemiplegia. Brain 1998, 121(Pt 3):515-526.

4. Berger W, Horstmann GA, Dietz V: Spastic paresis: impaired spinal reflexes and intact motor programs. J Neurol Neurosurg Psychiatry 1988, 51:568-571.

5. Adams RW, Gandevia SC, Skuse NF: The distribution of muscle weakness in upper motoneuron lesions affecting the lower limb. Brain 1990, 113(Pt 5):1459-1476. 
6. Clark DJ, Condliffe EG, Patten C: Activation impairment alters muscle torque-velocity in the knee extensors of persons with post-stroke hemiparesis. Clin Neurophysiol 2006, 117:2328-2337.

7. Lum PS, Patten C, Kothari D, Yap R: Effects of velocity on maximal torque production in poststroke hemiparesis. Muscle Nerve 2004, 30:732-742.

8. Harris JE, Eng JJ: Paretic upper-limb strength best explains arm activity in people with stroke. Phys Ther 2007, 87:88-97.

9. Wagner JM, Lang CE, Sahrmann SA, Hu Q, Bastian AJ, Edwards DF, Dromerick AW: Relationships between sensorimotor impairments and reaching deficits in acute hemiparesis. Neurorehabil Neural Repair 2006, 20:406-416

10. Patten C, Lexell J, Brown HE: Weakness and strength training in persons with poststroke hemiplegia: rationale, method, and efficacy. J Rehabil Res Dev 2004, 41:293-312.

11. Bobath B: Adult Hemiplegia: Evaluation and Treatment. 3rd edition. Oxford: Butterworth-Heineman Medical Books; 1990.

12. Fowler EG, Ho TW, Nwigwe Al, Dorey FJ: The effect of quadriceps femoris muscle strengthening exercises on spasticity in children with cerebral palsy. Phys Ther 2001, 81:1215-1223.

13. Miller GJT, Light KE: Strength training in spastic hemiparesis: should it be avoided? NeuroRehabilitation 1997, 9:17-28.

14. Dietz V, Quintern J, Berger W: Electrophysiological studies of gait in spasticity and rigidity. Evidence that altered mechanical properties of muscle contribute to hypertonia. Brain 1981, 104:431-449.

15. Brown DA, Kautz SA: Increased workload enhances force output during pedaling exercise in persons with poststroke hemiplegia. Stroke 1998, 29:598-606

16. Pak S, Patten C: Strengthening to promote functional recovery poststroke: an evidence-based review. Top Stroke Rehabil 2008, 15:177-199.

17. Teixeira-Salmela LF, Olney SJ, Nadeau S, Brouwer B: Muscle strengthening and physical conditioning to reduce impairment and disability in chronic stroke survivors. Arch Phys Med Rehabil 1999, 80:1211-1218.

18. Yang YR, Wang RY, Lin KH, Chu MY, Chan RC: Task-oriented progressive resistance strength training improves muscle strength and functional performance in individuals with stroke. Clin Rehabil 2006, 20:860-870

19. Flansbjer UB, Miller M, Downham D, Lexell J: Progressive resistance training after stroke: effects on muscle strength, muscle tone, gait performance and perceived participation. J Rehabil Med 2008, 40:42-48.

20. Ouellette MM, LeBrasseur NK, Bean JF, Phillips E, Stein J, Frontera WR, Fielding RA: High-intensity resistance training improves muscle strength, self-reported function, and disability in long-term stroke survivors. Stroke 2004, 35:1404-1409.

21. Patten C, Dozono J, Schmidt S, Jue M, Lum P: Combined functional task practice and dynamic high intensity resistance training promotes recovery of upper-extremity motor function in post-stroke hemiparesis: a case study. J Neurol Phys Ther 2006, 30:99-115.

22. Harris JE, Eng JJ: Strength training improves upper-limb function in individuals with stroke: a meta-analysis. Stroke 2010, 41:136-140

23. Corti M, McGuirk TE, Wu SS, Patten C: Differential Effects of Power Training Versus Functional Task Practice on Compensation and Restoration of Arm Function After Stroke. Neurorehabil Neural Repair 2012, 26:842-854

24. Wolf SL, Winstein CJ, Miller JP, Taub E, Uswatte G, Morris D, Giuliani C, Light $\mathrm{KE}$, Nichols-Larsen D: Effect of constraint-induced movement therapy on upper extremity function 3 to 9 months after stroke: the EXCITE randomized clinical trial. JAMA 2006, 296:2095-2104.

25. Mysiw WJ, Beegan JG, Gatens PF: Prospective cognitive assessment of stroke patients before inpatient rehabilitation. Am J Phys Med Rehabil 1989, 68(4):168-171.

26. Senn S: Cross-over trials in clinical research. 2nd edition. West Sussex: John Wiley \& Sons, Ltd.; 2002.

27. Fugl-Meyer AR, Jaasko L, Leyman I, Olsson S, Steglind S: The post-stroke hemiplegic patient. 1. a method for evaluation of physical performance. Scand I Rehabil Med 1975, 7:13-31.

28. Carr JH, Shepherd RB: A Motor Relearning Programme for Stroke. London: William Heinemann Medical Books; 1983.

29. Wressle E, Eeg-Olofsson AM, Marcusson J, Henriksson C: Improved client participation in the rehabilitation process using a client-centred goal formulation structure. J Rehabil Med 2002, 34:5-11.

30. Colson S, Pousson M, Martin A, Van Hoecke J: Isokinetic elbow flexion and coactivation following eccentric training. J Electromyogr Kinesiol 1999, 9:13-20.
31. Dvir Z: Isokinetics: testing, interpretation, and clinical application. New York: Churchill Livingstone; 1995.

32. Barak S, Duncan PW: Issues in selecting outcome measures to assess functional recovery after stroke. NeuroRx 2006, 3:505-524.

33. International Classification of Functioning, Disability and Health. [//www3. who.int/icf/icftemplate.cfm]

34. Ashworth B: Preliminary Trial of Carisoprodol in Multiple Sclerosis. Practitioner 1964, 192:540-542.

35. Pandyan AD, Johnson GR, Price Cl, Curless RH, Barnes MP, Rodgers H: A review of the properties and limitations of the Ashworth and modified Ashworth Scales as measures of spasticity. Clin Rehabil 1999, 13:373-383.

36. Wolf SL, Thompson PA, Morris DM, Rose DK, Winstein CJ, Taub E, Giulian C, Pearson SL: The EXCITE trial: attributes of the Wolf Motor Function Test in patients with subacute stroke. Neurorehabil Neural Repair 2005, 19:194-205.

37. Morris DM, Uswatte G, Crago JE, Cook EW 3rd, Taub E: The reliability of the wolf motor function test for assessing upper extremity function after stroke. Arch Phys Med Rehabil 2001, 82:750-755.

38. Wolf SL, Catlin PA, Ellis M, Archer AL, Morgan B, Piacentino A: Assessing Wolf motor function test as outcome measure for research in patients after stroke. Stroke 2001, 32:1635-1639.

39. Chang WC, Slaughter S, Cartwright D, Chan C: Evaluating the FONE FIM: Part I. Construct validity. J Outcome Meas 1997, 1:192-218.

40. Delagi EF, Perotto A: Anatomic Guide for the Electromyographer. Springfield, Illinois: Charles C. Thomas; 1981

41. Condliffe EG, Clark DJ, Patten C: Reliability of elbow stretch reflex assessment in chronic post-stroke hemiparesis. Clin Neurophysiol 2005, 116:1870-1878.

42. Kim M, Kothari DH, Lum PS, Patten C: Reliability of dynamic muscle performance in the hemiparetic upper limb. J Neurol Phys Ther 2005, 29:9-17.

43. Wolf SL, Segal RL, Catlin PA, Tschorn J, Raleigh T, Kontos H, Pate P. Determining consistency of elbow joint threshold angle in elbow flexor muscles with spastic hypertonia. Phys Ther 1996, 76:586-600.

44. Bailar JC, Hoaglin DC: Medical Uses of Statistics. Third edn: John Wiley and Sons; 2012.

45. Cohen J: A power primer. Psych Bull 1992, 112:155-159.

46. Haley SM, Fragala-Pinkham MA: Interpreting change scores of tests and measures used in physical therapy. Phys Ther 2006, 86:735-743.

47. Norman GR, Sloan JA, Wyrwich KW: Interpretation of changes in healthrelated quality of life: the remarkable universality of half a standard deviation. Med Care 2003, 41:582-592.

48. Enoka RM: Neuromechanics of Human Movement. 3rd edition. Champaign, IL: Human Kinetics; 2002.

49. Winstein CJ, Rose DK, Tan SM, Lewthwaite R, Chui HC, Azen SP: A randomized controlled comparison of upper-extremity rehabilitation strategies in acute stroke: A pilot study of immediate and long-term outcomes. Arch Phys Med Rehabil 2004, 85:620-628.

50. Thielman GT, Dean CM, Gentile AM: Rehabilitation of reaching after stroke: task-related training versus progressive resistive exercise. Arch Phys Med Rehabil 2004, 85:1613-1618.

51. Stein J, Krebs HI, Frontera WR, Fasoli SE, Hughes R, Hogan N: Comparison of two techniques of robot-aided upper limb exercise training after stroke. Am J Phys Med Rehabil 2004, 83:720-728.

52. Massy-Westropp NM, Gill TK, Taylor AW, Bohannon RW, Hill CL: Hand Grip Strength: age and gender stratified normative data in a populationbased study. BMC Res Notes 2011, 4:127.

53. Fleck SJ, Kraemer WJ: Designing Resistance Training Programs. 3rd edition. Champaign-Urbana: Human Kinetics; 2004

54. Chang JJ, Tung WL, Wu WL, Huang MH, Su FC: Effects of robot-aided bilateral force-induced isokinetic arm training combined with conventional rehabilitation on arm motor function in patients with chronic stroke. Arch Phys Med Rehabil 2007, 88:1332-1338.

55. Bohannon RW: Muscle strength and muscle training after stroke. J Rehabil Med 2007, 39:14-20.

56. Eng J): Strength training in individuals with stroke. Physiother Canada 2004, 56:189-201.

57. Remple MS, Bruneau RM, VandenBerg PM, Goertzen C, Kleim JA: Sensitivity of cortical movement representations to motor experience: evidence that skill learning but not strength training induces cortical reorganization. Behav Brain Res 2001, 123:133-141. 
58. Boroojerdi B, Ziemann U, Chen R, Butefisch CM, Cohen LG: Mechanisms underlying human motor system plasticity. Muscle Nerve 2001, 24:602-613

59. Porter MM: Power training for older adults. Appl Physiol Nutr Metab 2006, 31:87-94

60. Foldvari M, Clark M, Laviolette LC, Bernstein MA, Kaliton D, Castaneda C, Pu CT, Hausdorff JM, Fielding RA, Singh MA: Association of muscle power with functional status in community-dwelling elderly women. J Gerontol A Biol Sci Med Sci 2000, 55:M192-M199.

61. Clark DJ, Patten C, Reid KF, Carabello RJ, Phillips EM, Fielding RA: Impaired Voluntary Neuromuscular Activation Limits Muscle Power in MobilityLimited Older Adults. J Gerontol (A Biol Sci Med Sci) 2010, 65:495-502.

62. Leong B, Kamen G, Patten C, Burke JR: Maximal motor unit discharge rates in the quadriceps muscles of older weight lifters. Med Sci Sports Exerc 1999, 31:1638-1644.

63. Fielding RA, LeBrasseur NK, Cuoco A, Bean J, Mizer K, Fiatarone Singh MA: High-velocity resistance training increases skeletal muscle peak power in older women. J Am Geriatr Soc 2002, 50:655-662.

64. Carroll TJ, Riek S, Carson RG: The sites of neural adaptation induced by resistance training in humans. J Physiol 2002, 544:641-652.

65. Duchateau J, Enoka RM: Neural adaptations with chronic activity patterns in able-bodied humans. Am J Phys Med Rehabil 2002, 81:S17-S27.

66. Moritani T, DeVries A: Neural Factors Versus Hypertrophy in the Time Course of Muscle Strength Gain. Am J Phys Med 1979, 58:115-130.

67. Aagaard P: Training-induced changes in neural function. Exerc Sport SCi Rev 2003, 31:61-67.

68. Griffin L, Cafarelli E: Resistance training: cortical, spinal, and motor unit adaptations. Can J Appl Physiol 2005, 30:328-340.

69. Weier AT, Pearce AJ, Kidgell DJ: Strength training reduces intracortical inhibition. Acta Physiol (Oxf) 2012, 206:109-119.

70. Rothwell JC, Day BL, Thompson PD, Kujirai T: Short latency intracortical inhibition: one of the most popular tools in human motor neurophysiology. J Physiol 2009, 587:11-12.

71. Pascual-Leone A, Nguyet D, Cohen LG, Brasil-Neto JP, Cammarota A, Hallett M: Modulation of muscle responses evoked by transcranial magnetic stimulation during the acquisition of new fine motor skills. J Neurophysiol 1995, 74:1037-1045.

72. Nowak DA, Grefkes C, Ameli M, Fink GR: Interhemispheric competition after stroke: brain stimulation to enhance recovery of function of the affected hand. Neurorehabil Neural Repair 2009, 23:641-656.

73. Powers RK, Campbell DL, Rymer WZ: Stretch reflex dynamics in spastic elbow flexor muscles. Ann Neurol 1989, 25:32-42.

74. Heckman CJ: Alterations in synaptic input to motoneurons during partial spinal cord injury. Med Sci Sports Exerc 1994, 26:1480-1490.

75. Kuo JJ, Siddique T, Fu R, Heckman CJ: Increased persistent $\mathrm{Na}(+)$ current and its effect on excitability in motoneurones cultured from mutant SOD1 mice. J Physiol 2005, 563:843-854.

76. McPherson JG, Ellis MD, Heckman CJ, Dewald JP: Evidence for increased activation of persistent inward currents in individuals with chronic hemiparetic stroke. J Neurophysiol 2008, 100:3236-3243.

77. Delwaide PJ, Oliver E: Short-latency autogenic inhibition (IB inhibition) in human spasticity. J Neurol Neurosurg Psychiatry 1988, 51:1546-1550.

78. Thilmann AF, Fellows SJ, Garms E: Pathological stretch reflexes on the "good" side of hemiparetic patients. J Neurol Neurosurg Psychiatry 1990, 53:208-214.

79. Ibrahim IK, Berger W, Trippel M, Dietz V: Stretch-induced electromyographic activity and torque in spastic elbow muscles. Differential modulation of reflex activity in passive and active motor tasks. Brain 1993, 116(Pt 4):971-989.

80. Cody FW, Richardson HC, MacDermott N, Ferguson IT: Stretch and vibration reflexes of wrist flexor muscles in spasticity. Brain 1987, 110 (Pt 2):433-450

81. Mottram CJ, Suresh NL, Heckman CJ, Gorassini MA, Rymer WZ: Origins of abnormal excitability in biceps brachii motoneurons of spastic-paretic stroke survivors. I Neurophysiol 2009, 102:2026-2038.

82. Dobkin BH: Strategies for stroke rehabilitation. Lancet Neurol 2004 3:528-536

83. Kakuda W, Abo M, Shimizu M, Sasanuma J, Okamoto T, Yokoi A, Taguchi K, Mitani S, Harashima H, Urushidani N, Urashima M: A multi-center study on low-frequency rTMS combined with intensive occupational therapy for upper limb hemiparesis in post-stroke patients. J Neuroeng Rehabil 2012, 9:4.

84. Whitall J, McCombe Waller S, Silver KH, Macko RF: Repetitive bilateral arm training with rhythmic auditory cueing improves motor function in chronic hemiparetic stroke. Stroke 2000, 31:2390-2395.

85. Stufken J: Optimal Crossover Designs. In Design and Analysis of Experiments Handbook of Statistics. Edited by Ghosh S, Rao CR. Elsevier: Amsterdam; 1996:63-90.

doi:10.1186/1743-0003-10-1

Cite this article as: Patten et al:: Concurrent neuromechanical and functional gains following upper-extremity power training post-stroke. Journal of NeuroEngineering and Rehabilitation 2013 10:1.

\section{Submit your next manuscript to BioMed Central and take full advantage of:}

- Convenient online submission

- Thorough peer review

- No space constraints or color figure charges

- Immediate publication on acceptance

- Inclusion in PubMed, CAS, Scopus and Google Scholar

- Research which is freely available for redistribution 